\title{
Fredholm alternative for the second-order singular Dirichlet problem
}

\section{Alexander Lomtatidze ${ }^{1,2}$ and Zdeněk Oplušti $2^{2^{*}}$}

\author{
"Correspondence: \\ oplustil@fme.vutbr.cz \\ ${ }^{2}$ Faculty of Mechanical Engineering, \\ Institute of Mathematics, Brno \\ University of Technology, Technická \\ 2, Brno, 616 69, Czech Republic \\ Full list of author information is \\ available at the end of the article
}

\author{
Abstract \\ Consider the singular Dirichlet problem$$
u^{\prime \prime}=p(t) u+q(t) ; \quad u(a)=0, \quad u(b)=0,
$$ \\ where $p, q:] a, b[\rightarrow \mathbb{R}$ are locally Lebesgue integrable functions. It is proved that if

$$
\int_{a}^{b}(s-a)(b-s)[p(s)]_{-} d s<+\infty
$$

then the Fredholm alternative remains true.

MSC: $34 \mathrm{~B} 05$

Keywords: singular Dirichlet problem; Fredholm alternative

\section{Introduction}

Consider the boundary value problem

$$
\begin{aligned}
& u^{\prime \prime}=p(t) u+q(t), \\
& u(a)=0, \quad u(b)=0,
\end{aligned}
$$

where $p, q \in L_{\mathrm{loc}}(] a, b[)$. We are mainly interested in the case when the functions $p$ and $q$ are not (in general) integrable on $[a, b]$. In this case, equation (1) as well as problem (1), (2) are said to be singular. It is well known that for singular problem (1), (2), the condition

$$
\int_{a}^{b}(s-a)(b-s)|p(s)| d s<+\infty
$$

guarantees the validity of the Fredholm alternative. More precisely, if (3) holds, then problem (1), (2) is uniquely solvable for any $q$ satisfying

$$
\int_{a}^{b}(s-a)(b-s)|q(s)| d s<+\infty
$$

iff the corresponding homogeneous equation

$$
u^{\prime \prime}=p(t) u
$$

2014 Lomtatidze and Opluštil; licensee Springer. This is an Open Access article distributed under the terms of the Creative Commons Attribution License (http://creativecommons.org/licenses/by/2.0), which permits unrestricted use, distribution, and reproduction in any medium, provided the original work is properly cited. 
has no nontrivial solution satisfying (2). The above statement plays an important role in the theory of singular problems; however, it does not cover many interesting, even rather simple, equations. For example, consider the Dirichlet problem for the Euler equation

$$
u^{\prime \prime}=\frac{\alpha}{(t-a)^{2}} u+\beta ; \quad u(a)=0, \quad u(b)=0,
$$

where $\alpha$ and $\beta$ are real constants. By direct calculations, one can easily verify that if $\alpha>0$, then the homogeneous problem

$$
u^{\prime \prime}=\frac{\alpha}{(t-a)^{2}} u ; \quad u(a)=0, \quad u(b)=0
$$

has only the trivial solution, while problem (5) is uniquely solvable. However, in this case $p(t)=\frac{\alpha}{(t-a)^{2}}$ and therefore condition (3) is not satisfied.

The aim of this paper is to show that the Fredholm alternative remains true even in the case when instead of (3) only the condition

$$
\int_{a}^{b}(s-a)(b-s)[p(s)]_{-} d s<+\infty
$$

holds. The paper is organized as follows. At the end of this section, we state our main results, the proofs of which one can find in Section 4. In Section 2, we recall some known results in a suitable for us form. Section 3 is devoted to a priori estimates and plays a crucial role in the proofs of the main results.

Throughout the paper we use the following notation.

$\mathbb{R}$ is the set of real numbers.

For $x \in \mathbb{R}$, we put $[x]_{-}=\frac{1}{2}(|x|-x)$.

$C(I)$, where $I \subset \mathbb{R}$ is the set of continuous functions $u: I \rightarrow \mathbb{R}$.

For $u \in C([\alpha, \beta])$, we put $\|u\|_{[\alpha, \beta]}=\max \{|u(t)|: t \in[\alpha, \beta]\}$.

$A C_{\mathrm{loc}}^{\prime}(] \alpha, \beta[)$ is the set of functions $\left.u:\right] \alpha, \beta[\rightarrow \mathbb{R}$, which are absolutely continuous together with their first derivative on every closed subinterval of $] \alpha, \beta[$.

$L_{\mathrm{loc}}(] \alpha, \beta[)$ is the set of functions $\left.p:\right] \alpha, \beta[\rightarrow \mathbb{R}$, which are Lebesgue integrable on every closed subinterval of $] \alpha, \beta[$.

By $f(a)$ (resp., $f(b))$ we denote the right (resp., left) limit of the function $f:] a, b[\rightarrow \mathbb{R}$ at the point $a$ (resp., $b$ ).

Under a solution of equation (1) we understand a function $u \in A C_{\mathrm{loc}}^{\prime}(] a, b[)$ which satisfies it almost everywhere in $] a, b$. A solution of equation (1) satisfying (2) is said to be a solution of problem (1), (2).

We say that a certain property holds in $] \alpha, \beta$ [ if it takes place on every closed subinterval of $] \alpha, \beta[$.

Recall that we consider problem (1), (2), where $p, q \in L_{\mathrm{loc}}(] a, b[)$. Our main results are the following.

Theorem 1.1 Let condition (6) hold. Then problem (1), (2) is uniquely solvable for any $q$ satisfying (4) iff homogeneous problem $\left(1_{0}\right)$, (2) has no nontrivial solution. 
Remark 1.1 In Theorem 1.1, condition (4) is essential and cannot be omitted. Indeed, let $p \equiv 0, q \in L_{\mathrm{loc}}(] a, b[), q(t) \geq 0$ for $\left.t \in\right] a, b[$, and

$$
\int_{a}^{\frac{a+b}{2}}(s-a) q(s) d s=+\infty
$$

Evidently, (6) holds and problem $\left(1_{0}\right),(2)$ has no nontrivial solution. On the other hand, a general solution of (1) is of the form

$$
\left.u(t)=\alpha+\beta t+\int_{t}^{\frac{a+b}{2}}(s-a) q(s) d s-(t-a) \int_{t}^{\frac{a+b}{2}} q(s) d s \quad \text { for } t \in\right] a, b[.
$$

However, for $a<t<x<\frac{a+b}{2}$, we have

$$
u(t) \geq \int_{x}^{\frac{a+b}{2}}(s-a) q(s) d s-(t-a) \int_{x}^{\frac{a+b}{2}} q(s) d s+\alpha+\beta t .
$$

Hence,

$$
\liminf _{t \rightarrow a+} u(t) \geq \alpha+\beta a+\int_{x}^{\frac{a+b}{2}}(s-a) q(s) d s .
$$

Therefore, in view of (7), we get $\lim _{t \rightarrow a+} u(t)=+\infty$ and, consequently, problem (1), (2) has no solution.

Remark 1.2 Theorem 1.1 concerns half homogeneous problem (1), (2) and does not remain true for the fully nonhomogeneous problem

$$
u^{\prime \prime}=p(t) u+q(t) ; \quad u(a)=c_{1}, \quad u(b)=c_{2} .
$$

Let, for example, $p(t)=\frac{2}{(t-a)^{2}}, q \equiv 0, c_{1} \neq 0$, and $c_{2}=0$. It is clear that (6) holds and the corresponding homogeneous problem $\left(1_{0}\right),(2)$ has no nontrivial solution. On the other hand, a general solution of (1) is of the form $u(t)=\frac{\alpha}{t-a}+\beta(t-a)^{2}$ for $\left.t \in\right] a, b$ [ and, therefore, (8) has no solution.

Theorem 1.2 Let (6) hold and problem (1 $\left.1_{0}\right),(2)$ have no nontrivial solution. Then there exists $r>0$ such that for any $q$ satisfying (4), the solution $u$ of problem (1), (2) admits the estimate

$$
\left.|u(t)|+(t-a)(b-t)\left|u^{\prime}(t)\right| \leq r \int_{a}^{b}(s-a)(b-s)|q(s)| d s \quad \text { for } t \in\right] a, b[.
$$

Consider now a sequence of equations

$$
u^{\prime \prime}=p(t) u+q_{n}(t)
$$

where $q_{n} \in L_{\mathrm{loc}}(] a, b[)$ are such that

$$
\int_{a}^{b}(s-a)(b-s)\left|q_{n}(s)\right| d s<+\infty \quad \text { for } n=1,2, \ldots
$$


Let, moreover, $q \in L_{\mathrm{loc}}(] a, b[)$ satisfy (4) and

$$
\lim _{n \rightarrow+\infty} \int_{a}^{b}(s-a)(b-s)\left|q_{n}(s)-q(s)\right| d s=0 .
$$

Corollary 1.1 Let (4), (6) hold and problem $\left(1_{0}\right)$, (2) have no nontrivial solution. Let, moreover, (11) and (12) be fulfilled. Then the problems (1), (2) and $\left(10_{n}\right),(2)$ have unique solutions $u$ and $u_{n}$, respectively,

$$
\lim _{n \rightarrow+\infty} u_{n}(t)=u(t) \quad \text { uniformly on }[a, b]
$$

and

$$
\left.\lim _{n \rightarrow+\infty} u_{n}^{\prime}(t)=u^{\prime}(t) \quad \text { uniformly in }\right] a, b[.
$$

\section{Auxiliary statements}

In this section, we consider the equation

$$
v^{\prime \prime}=h(t) v+q(t)
$$

where $h, q \in L_{\mathrm{loc}}(] a, b[), q$ satisfies (4), and

$$
\int_{a}^{b}(s-a)(b-s)|h(s)| d s<+\infty
$$

Below we state some known results in a suitable for us form.

Proposition 2.1 Let (15) hold. Then the problem

$$
v^{\prime \prime}=h(t) v+q(t) ; \quad v(a)=c_{1}, \quad v(b)=c_{2}
$$

is uniquely solvable for any $c_{1}, c_{2} \in \mathbb{R}$ and $q$ satisfying (4) iff the homogeneous problem

$$
v^{\prime \prime}=h(t) v ; \quad v(a)=0, \quad v(b)=0
$$

has no nontrivial solution.

Proof See, e.g., [1, Theorem 3.1] or [2, Theorem 1.1].

Proposition 2.2 Let (15) hold. Then there exist $\left.a_{0} \in\right] a, b\left[\right.$ and $\left.b_{0} \in\right] a_{0}, b[$ such that, for any $t_{1}<t_{2}$ satisfying either $t_{1}, t_{2} \in\left[a, a_{0}\right]$ or $t_{1}, t_{2} \in\left[b_{0}, b\right]$, the homogeneous problem

$$
v^{\prime \prime}=h(t) v ; \quad v\left(t_{1}\right)=0, \quad v\left(t_{2}\right)=0
$$

has no nontrivial solution. Moreover, for any $w \in C_{\mathrm{loc}}^{\prime}(] t_{1}, t_{2}[)$ (where $t_{1}<t_{2}$ are the same as above) satisfying

$$
\left.w^{\prime \prime}(t) \geq h(t) w(t) \quad \text { for } t \in\right] t_{1}, t_{2}\left[; \quad w\left(t_{1}\right)=0, \quad w\left(t_{2}\right)=0,\right.
$$


the inequality

$$
w(t) \leq 0 \quad \text { for } t \in\left[t_{1}, t_{2}\right]
$$

holds.

Proof In view of (15), there exist $\left.a_{0} \in\right] a, b\left[\right.$ and $\left.b_{0} \in\right] a_{0}, b[$ such that

$$
\int_{a}^{a_{0}}(s-a)|h(s)| d s<1, \quad \int_{b_{0}}^{b}(b-s)|h(s)| d s<1 .
$$

Hence, the inequalities

$$
\int_{a}^{a_{0}}(s-a)\left(a_{0}-s\right)|h(s)| d s<a_{0}-a, \quad \int_{b_{0}}^{b}\left(s-b_{0}\right)(b-s)|h(s)| d s<b-b_{0}
$$

hold as well. The latter inequalities, by virtue of [2, Lemma 4.1], imply that for any $t_{1}<t_{2}$ satisfying either $t_{1}, t_{2} \in\left[a, a_{0}\right]$ or $t_{1}, t_{2} \in\left[b_{0}, b\right]$, homogeneous problem (16) has no nontrivial solution.

The second part of the proposition follows easily from the above-proved part and [2, Lemma 1.3].

Proposition 2.3 Let (15) hold. Let, moreover, $\left.a_{0} \in\right] a, b\left[\right.$ and $\left.b_{0} \in\right] a_{0}, b[$ be from the assertion of Proposition 2.2. Then there exists $\varrho>0$ such that for any $c \in \mathbb{R}$ and any $q$ satisfying (4), the solution $v$ of the problem

$$
v^{\prime \prime}=h(t) v+q(t) ; \quad v(a)=0, \quad v\left(a_{0}\right)=c
$$

admits the estimate

$$
|v(t)| \leq \varrho\left(|c|(t-a)+\int_{a}^{t}(s-a)|q(s)| d s+(t-a) \int_{t}^{a_{0}}|q(s)| d s\right)
$$

for $\left.t \in] a, a_{0}\right]$, while the solution $v$ of the problem

$$
v^{\prime \prime}=h(t) v+q(t) ; \quad v\left(b_{0}\right)=c, \quad v(b)=0
$$

admits the estimate

$$
|v(t)| \leq \varrho\left(|c|(b-t)+\int_{t}^{b}(b-s)|q(s)| d s+(b-t) \int_{b_{0}}^{t}|q(s)| d s\right)
$$

for $t \in\left[b_{0}, b[\right.$.

Proof By virtue of (15) and [1, Lemma 2.2], the initial value problems

$$
v_{1}^{\prime \prime}=h(t) v_{1} ; \quad v_{1}(a)=0, \quad v_{1}^{\prime}(a)=1
$$


and

$$
v_{2}^{\prime \prime}=h(t) v_{2} ; \quad v_{2}\left(a_{0}\right)=0, \quad v_{2}^{\prime}\left(a_{0}\right)=-1
$$

have unique solutions $v_{1}$ and $v_{2}$, respectively, and the estimates

$$
\left|v_{1}(t)\right| \leq \varrho_{0}(t-a), \quad\left|v_{2}(t)\right| \leq \varrho_{0}\left(a_{0}-t\right) \quad \text { for } t \in\left[a, a_{0}\right]
$$

are fulfilled, where

$$
\varrho_{0}=\exp \left(2 \int_{a}^{a_{0}}(s-a)|h(s)| d s\right)
$$

On the other hand, by virtue of Proposition 2.2,

$$
v_{1}\left(a_{0}\right) \neq 0 \quad \text { and } \quad v_{2}(a) \neq 0 \text {. }
$$

In view of Propositions 2.1 and 2.2, problem (17) has a unique solution $v$. By direct calculations, one can easily verify that

$$
v(t)=\frac{c}{v_{1}\left(a_{0}\right)} v_{1}(t)-\frac{1}{v_{2}(a)}\left(v_{2}(t) \int_{a}^{t} v_{1}(s) q(s) d s+v_{1}(t) \int_{t}^{a_{0}} v_{2}(s) q(s) d s\right)
$$

for $t \in\left[a, a_{0}\right]$. Analogously, the (unique) solution $v$ of problem (19) is of the form

$$
v(t)=\frac{c}{v_{4}\left(b_{0}\right)} v_{4}(t)-\frac{1}{v_{3}(b)}\left(v_{4}(t) \int_{b_{0}}^{t} v_{3}(s) q(s) d s+v_{3}(t) \int_{t}^{b} v_{4}(s) q(s) d s\right)
$$

for $t \in\left[b_{0}, b\right]$, where $v_{3}$ and $v_{4}$ are solutions of the problems

$$
v_{3}^{\prime \prime}=h(t) v_{3} ; \quad v_{3}\left(b_{0}\right)=0, \quad v_{3}^{\prime}\left(b_{0}\right)=1
$$

and

$$
v_{4}^{\prime \prime}=h(t) v_{4} ; \quad v_{4}(b)=0, \quad v_{4}^{\prime}(b)=-1,
$$

respectively, $v_{3}(b) \neq 0, v_{4}\left(b_{0}\right) \neq 0$, and the estimates

$$
\left|v_{3}(t)\right| \leq \varrho_{1}\left(t-b_{0}\right), \quad\left|v_{4}(t)\right| \leq \varrho_{1}(b-t) \quad \text { for } t \in\left[b_{0}, b\right]
$$

are fulfilled with

$$
\varrho_{1}=\exp \left(2 \int_{b_{0}}^{b}(b-s)|h(s)| d s\right)
$$

Now, it follows from (22) and (23), in view of (21) and (24), that the estimates (18) and (20) hold with

$$
\varrho=\frac{\rho_{0}}{\left|v_{1}\left(a_{0}\right)\right|}+\frac{\rho_{1}}{\left|v_{4}\left(b_{0}\right)\right|}+\frac{a_{0}-a}{\left|v_{2}(a)\right|} \varrho_{0}^{2}+\frac{b-b_{0}}{\left|\nu_{3}(b)\right|} \varrho_{1}^{2} .
$$




\section{Lemmas on a priori estimates}

Lemma 3.1 Let (4) and (6) hold. Then, for any $\alpha \in[a, b[$ and $\beta \in] \alpha, b]$, every solution $u$ of equation (1) satisfying

$$
u(\alpha)=0, \quad u(\beta)=0
$$

admits the estimate

$$
\begin{aligned}
(t-a)(b-t)\left|u^{\prime}(t)\right| \leq & \|u\|_{[\alpha, \beta]}\left(b-a+\int_{a}^{b}(s-a)(b-s)[p(s)]_{-} d s\right) \\
& \left.+\int_{a}^{b}(s-a)(b-s)|q(s)| d s \quad \text { for } t \in\right] \alpha, \beta[.
\end{aligned}
$$

Proof Let $\left.t_{0} \in\right] \alpha, \beta[$. Then it is clear that either

$$
u\left(t_{0}\right) u^{\prime}\left(t_{0}\right)>0
$$

or

$$
u\left(t_{0}\right) u^{\prime}\left(t_{0}\right)<0
$$

or

$$
u\left(t_{0}\right) u^{\prime}\left(t_{0}\right)=0
$$

Assume that (27) (resp., (28)) holds. Then, in view of (25), there is $\left.t^{*} \in\right] t_{0}, \beta[$ (resp., $\left.t_{*} \in\right] \alpha, t_{0}[)$ such that

$$
\begin{aligned}
& u(t) \operatorname{sgn} u^{\prime}\left(t_{0}\right)>0 \text { for } t \in\left[t_{0}, t^{*}\right] \text { and } u^{\prime}\left(t^{*}\right)=0 \\
& \left(\text { resp., } u(t) \operatorname{sgn} u^{\prime}\left(t_{0}\right)<0 \text { for } t \in\left[t_{*}, t_{0}\right] \text { and } u^{\prime}\left(t_{*}\right)=0\right) .
\end{aligned}
$$

Multiplying both sides of (1) by $b-t$ (resp., by $t-a$ ) and integrating it from $t_{0}$ to $t^{*}$ (resp., from $t_{*}$ to $t_{0}$ ), we get

$$
\begin{aligned}
& \left(b-t_{0}\right) u^{\prime}\left(t_{0}\right)=u\left(t^{*}\right)-u\left(t_{0}\right)-\int_{t_{0}}^{t^{*}}(b-s)(p(s) u(s)+q(s)) d s \\
& \left(\text { resp., }\left(t_{0}-a\right) u^{\prime}\left(t_{0}\right)=u\left(t_{0}\right)-u\left(t_{*}\right)+\int_{t_{*}}^{t_{0}}(s-a)(p(s) u(s)+q(s)) d s\right) .
\end{aligned}
$$

Hence, in view of (30), we obtain

$$
\begin{aligned}
& \left(b-t_{0}\right)\left|u^{\prime}\left(t_{0}\right)\right| \leq\|u\|_{[\alpha, \beta]}\left(1+\int_{t_{0}}^{b}(b-s)[p(s)]_{-} d s\right)+\int_{t_{0}}^{b}(b-s)|q(s)| d s \\
& \left(\left(t_{0}-a\right)\left|u^{\prime}\left(t_{0}\right)\right| \leq\|u\|_{[\alpha, \beta]}\left(1+\int_{a}^{t_{0}}(s-a)[p(s)]_{-} d s\right)+\int_{a}^{t_{0}}(s-a)|q(s)| d s\right) .
\end{aligned}
$$


Multiplying both parts of the latter inequality by $t_{0}-a$ (resp., by $b-t_{0}$ ), we get

$$
\begin{aligned}
\left(t_{0}-a\right)\left(b-t_{0}\right)\left|u^{\prime}\left(t_{0}\right)\right| \leq & \|u\|_{[\alpha, \beta]}\left(b-a+\int_{a}^{b}(s-a)(b-s)[p(s)]_{-} d s\right) \\
& +\int_{a}^{b}(s-a)(b-s)|q(s)| d s .
\end{aligned}
$$

Suppose now that (29) holds. Then either there is $\left.\beta_{0} \in\right] t_{0}, \beta[$ such that

$$
u(t) u^{\prime}(t)=0 \quad \text { for } t \in\left[t_{0}, \beta_{0}\right]
$$

or there is a sequence $\left.\left\{t_{n}\right\}_{n=1}^{+\infty} \subset\right] t_{0}, \beta[$ such that

$$
\begin{aligned}
& \lim _{n \rightarrow+\infty} t_{n}=t_{0}, \\
& u\left(t_{n}\right) u^{\prime}\left(t_{n}\right) \neq 0 \quad \text { for } n \in \mathbb{N} .
\end{aligned}
$$

If (32) holds, then evidently $u(t)=u\left(t_{0}\right)$ for $t \in\left[t_{0}, \beta_{0}\right]$ and, consequently, (31) is fulfilled. On the other hand, if (34) holds, then, by virtue of the above-proved, the inequalities

$$
\begin{aligned}
\left(t_{n}-a\right)\left(b-t_{n}\right)\left|u^{\prime}\left(t_{n}\right)\right| \leq & \|u\|_{[\alpha, \beta]}\left(b-a+\int_{a}^{b}(s-a)(b-s)[p(s)]_{-} d s\right) \\
& +\int_{a}^{b}(s-a)(b-s)|q(s)| d s \quad \text { for } n=1,2, \ldots
\end{aligned}
$$

are fulfilled, and therefore, in view of (33), inequality (31) holds as well. Thus, estimate (26) is fulfilled.

Lemma 3.2 Let (6) hold. Then there exist $\left.a_{0} \in\right] a, b\left[, b_{0} \in\right] a_{0}, b[$, and $\varrho>0$ such that for any $\alpha \in\left[a, a_{0}[, \beta \in] b_{0}, b\right]$ and any $q$ satisfying (4), every solution $u$ of equation (1) satisfying

$$
u(\alpha)=0
$$

admits the estimate

$$
\begin{aligned}
& |u(t)| \leq \varrho\left((t-a)\|u\|_{\left[\alpha, a_{0}\right]}+\int_{a}^{t}(s-a)|q(s)| d s+(t-a) \int_{t}^{a_{0}}|q(s)| d s\right) \\
& \left.\quad \text { for } t \in] \alpha, a_{0}\right],
\end{aligned}
$$

while every solution $u$ of equation (1) satisfying

$$
u(\beta)=0
$$

admits the estimate

$$
\begin{aligned}
& |u(t)| \leq \varrho\left((b-t)\|u\|_{\left[b_{0}, \beta\right]}+\int_{t}^{b}(b-s)|q(s)| d s+(b-t) \int_{b_{0}}^{t}|q(s)| d s\right) \\
& \quad \text { for } t \in\left[b_{0}, \beta[.\right.
\end{aligned}
$$


Proof Let $a_{0}, b_{0}$, and $\varrho$ be from the assertion of Propositions 2.2 and 2.3 with $h(t)=$ $-[p(t)]_{-}$for $\left.t \in\right] a, b\left[\right.$. Let, moreover, $\alpha \in\left[a, a_{0}[\right.$ (resp., $\left.\beta \in] b_{0}, b\right]$ ) and $u$ be a solution of problem (1), (35) (resp., (1), (37)). By virtue of Propositions 2.2 and 2.3, the problem

$$
\begin{aligned}
& v^{\prime \prime}=-[p(t)]_{-} v-|q(t)|, \\
& v(a)=0, \quad v\left(a_{0}\right)=\|u\|_{\left[\alpha, a_{0}\right]} \quad\left(\text { resp., } v\left(b_{0}\right)=\|u\|_{\left[b_{0}, \beta\right]}, \quad v(b)=0\right)
\end{aligned}
$$

has a unique solution $v$ and, moreover, for any $\left.t \in] a, a_{0}\right]$ (resp., $t \in\left[b_{0}, b[\right.$ ), the estimate

$$
\begin{aligned}
& 0 \leq v(t) \leq \varrho\left((t-a)\|u\|_{\left[\alpha, a_{0}\right]}+\int_{a}^{t}(s-a)|q(s)| d s+(t-a) \int_{t}^{a_{0}}|q(s)| d s\right) \\
& \left(\text { resp., } 0 \leq v(t) \leq \varrho\left((b-t)\|u\|_{\left[b_{0}, \beta\right]}+\int_{t}^{b}(b-s)|q(s)| d s+(b-t) \int_{b_{0}}^{t}|q(s)| d s\right)\right)
\end{aligned}
$$

holds. Let us show that

$$
\left.|u(t)| \leq v(t) \quad \text { for } t \in\left[\alpha, a_{0}\right] \text { (resp., for } t \in\left[b_{0}, \beta\right]\right) \text {. }
$$

Assume the contrary, let (41) be violated. Define

$$
\left.w(t)=|u(t)|-v(t) \quad \text { for } t \in\left[\alpha, a_{0}\right] \text { (resp., for } t \in\left[b_{0}, \beta\right]\right) .
$$

Then there exist $t_{1} \in\left[\alpha, a_{0}\left[\right.\right.$ and $\left.\left.t_{2} \in\right] t_{1}, a_{0}\right]$ (resp., $t_{1} \in\left[b_{0}, \beta\left[\right.\right.$ and $\left.\left.t_{2} \in\right] t_{1}, \beta\right]$ ) such that

$$
\begin{aligned}
& w(t)>0 \quad \text { for } t \in] t_{1}, t_{2}[ \\
& w\left(t_{1}\right)=0, \quad w\left(t_{2}\right)=0 .
\end{aligned}
$$

In view of (1), (39), and (42), it is clear that $w \in A C_{\mathrm{loc}}^{\prime}(] t_{1}, t_{2}[)$ and

$$
\left.w^{\prime \prime}(t)=p(t)|u(t)|+q(t) \operatorname{sgn} u(t)+[p(t)]_{-} v(t)+|q(t)| \geq-[p(t)]_{-} w(t) \quad \text { for } t \in\right] t_{1}, t_{2}[.
$$

Hence, by virtue of (43) and Proposition 2.2, we get $w(t) \leq 0$ for $t \in] t_{1}, t_{2}[$, which contradicts (42). Therefore, (41) is fulfilled. The estimate (36) (resp., (38)) now follows from (40) and (41).

Lemma 3.3 Let (6) hold and problem (1 $\left.1_{0}\right)$, (2) have no nontrivial solution. Then there exist $\left.\bar{a}_{0} \in\right] a, b\left[, \bar{b}_{0} \in\right] \bar{a}_{0}, b\left[\right.$, and $r_{0}>0$ such that for any $\alpha \in\left[a, \bar{a}_{0}\right]$ and $\beta \in\left[\bar{b}_{0}, b\right]$ and any $q$ satisfying (4), every solution $u$ of equation (1) satisfying

$$
u(\alpha)=0, \quad u(\beta)=0
$$

admits the estimate

$$
|u(t)| \leq r_{0} \int_{a}^{b}(s-a)(b-s)|q(s)| d s \quad \text { for } t \in[\alpha, \beta] .
$$


Proof Suppose to the contrary that the lemma is not true. Then there exist sequences $\left\{a_{n}\right\}_{n=1}^{+\infty} \subset\left[a, \frac{a+b}{2}\left[,\left\{b_{n}\right\}_{n=1}^{+\infty} \subset\right] \frac{a+b}{2}, b\right],\left\{q_{n}\right\}_{n=1}^{+\infty} \subset L_{\mathrm{loc}}(] a, b[)$, and $\left\{u_{n}\right\}_{n=1}^{+\infty} \subset A C_{\mathrm{loc}}^{\prime}(] a, b[)$ such that (11) holds,

$$
\begin{aligned}
& \lim _{n \rightarrow+\infty} a_{n}=a, \quad \lim _{n \rightarrow+\infty} b_{n}=b, \\
& \left.u_{n}^{\prime \prime}(t)=p(t) u_{n}(t)+q_{n}(t) \quad \text { for } t \in\right] a, b\left[, \quad u_{n}\left(a_{n}\right)=0 \quad u_{n}\left(b_{n}\right)=0\right.
\end{aligned}
$$

and

$$
\left\|u_{n}\right\|_{\left[a_{n}, b_{n}\right]}>n \int_{a}^{b}(s-a)(b-s)\left|q_{n}(s)\right| d s \quad \text { for } n=1,2, \ldots
$$

Introduce the notation

$$
\tilde{u}_{n}(t)=\frac{1}{\left\|u_{n}\right\|_{\left[a_{n}, b_{n}\right]}} u_{n}(t), \quad \tilde{q}_{n}(t)=\frac{1}{\left\|u_{n}\right\|_{\left[a_{n}, b_{n}\right]}} q_{n}(t) .
$$

Then it is clear that

$$
\left\|\tilde{u}_{n}\right\|_{\left[a_{n}, b_{n}\right]}=1
$$

and

$$
\left.\tilde{u}_{n}^{\prime \prime}(t)=p(t) \tilde{u}_{n}(t)+\tilde{q}_{n}(t) \quad \text { for } t \in\right] a_{n}, b_{n}\left[, \quad \tilde{u}_{n}\left(a_{n}\right)=0, \quad \tilde{u}_{n}\left(b_{n}\right)=0 .\right.
$$

Moreover, it follows from (45) that

$$
\lim _{n \rightarrow+\infty} \int_{a}^{b}(s-a)(b-s)\left|\tilde{q}_{n}(s)\right| d s=0
$$

and, consequently,

$$
\left.\lim _{n \rightarrow+\infty} \int_{\frac{a+b}{2}}^{t}\left(\int_{\frac{a+b}{2}}^{s} \tilde{q}_{n}(\xi) d \xi\right) d s=0 \quad \text { for } t \in\right] a, b[.
$$

By virtue of Lemma 3.1, (46), and (47),

$$
\begin{aligned}
(t-a)(b-t)\left|\tilde{u}_{n}^{\prime}(t)\right| \leq & b-a+\int_{a}^{b}(s-a)(b-s)[p(s)]_{-} d s \\
& \left.+\int_{a}^{b}(s-a)(b-s)\left|\tilde{q}_{n}(s)\right| d s \quad \text { for } t \in\right] a_{n}, b_{n}[.
\end{aligned}
$$

Hence, in view of (44) and (48), the sequence $\left\{\tilde{u}_{n}^{\prime}\right\}_{n=1}^{+\infty}$ is uniformly bounded in $] a, b[$ and, therefore, the sequence $\left\{\tilde{u}_{n}\right\}_{n=1}^{+\infty}$ is equicontinuous in $] a, b$. Taking, moreover, into account (46), by virtue of the Arzelá-Ascoli lemma, we can assume, without loss of generality, that

$$
\left.\lim _{n \rightarrow+\infty} \tilde{u}_{n}(t)=u_{0}(t) \quad \text { uniformly in }\right] a, b[\text {, }
$$


where $u_{0} \in C(] a, b[)$ and, moreover,

$$
\lim _{n \rightarrow+\infty} \tilde{u}_{n}^{\prime}\left(\frac{a+b}{2}\right)=c_{0}
$$

By a direct calculation, one can easily verify that

$$
\begin{aligned}
\tilde{u}_{n}(t)= & \tilde{u}_{n}\left(\frac{a+b}{2}\right)+\left(t-\frac{a+b}{2}\right) \tilde{u}_{n}^{\prime}\left(\frac{a+b}{2}\right) \\
& \left.+\int_{\frac{a+b}{2}}^{t}\left(\int_{\frac{a+b}{2}}^{s}\left[p(\xi) \tilde{u}_{n}(\xi)+\tilde{q}_{n}(\xi)\right] d \xi\right) d s \quad \text { for } t \in\right] a, b[,
\end{aligned}
$$

whence, in view of (49)-(51), we get

$$
\left.u_{0}(t)=u_{0}\left(\frac{a+b}{2}\right)+\left(t-\frac{a+b}{2}\right) c_{0}+\int_{\frac{a+b}{2}}^{t}\left(\int_{\frac{a+b}{2}}^{s} p(\xi) u_{0}(\xi) d \xi\right) d s \quad \text { for } t \in\right] a, b[\text {. }
$$

Thus $u_{0} \in A C_{\mathrm{loc}}^{\prime}(] a, b[)$ and $u_{0}$ is a solution of equation $\left(1_{0}\right)$.

Now let $\left.a_{0} \in\right] a, b\left[, b_{0} \in\right] a_{0}, b[$, and $\varrho>0$ be from the assertion of Lemma 3.2. Assume, without loss of generality, that $a_{n}<a_{0}$ and $b_{n}>b_{0}$ for any natural $n$. Then, by virtue of Lemma 3.2, (46), and (47), the estimates

$$
\begin{aligned}
& \left.\left.\left|\tilde{u}_{n}(t)\right| \leq \varrho\left(t-a+\int_{a}^{t}(s-a)\left|\tilde{q}_{n}(s)\right| d s+(t-a) \int_{t}^{a_{0}}\left|\tilde{q}_{n}(s)\right| d s\right) \quad \text { for } t \in\right] a_{n}, a_{0}\right], \\
& \left|\tilde{u}_{n}(t)\right| \leq \varrho\left(b-t+\int_{t}^{b}(b-s)\left|\tilde{q}_{n}(s)\right| d s+(b-t) \int_{b_{0}}^{t}\left|\tilde{q}_{n}(s)\right| d s\right) \quad \text { for } t \in\left[b_{0}, b_{n}[\right.
\end{aligned}
$$

are fulfilled. Moreover, in view of (48), we have

$$
\left.\left.\lim _{n \rightarrow+\infty}\left(\int_{a}^{t}(s-a)\left|\tilde{q}_{n}(s)\right| d s+(t-a) \int_{t}^{a_{0}}\left|\tilde{q}_{n}(s)\right| d s\right)=0 \quad \text { for } t \in\right] a, a_{0}\right]
$$

and

$$
\lim _{n \rightarrow+\infty}\left(\int_{t}^{b}(b-s)\left|\tilde{q}_{n}(s)\right| d s+(b-t) \int_{b_{0}}^{t}\left|\tilde{q}_{n}(s)\right| d s\right)=0 \quad \text { for } t \in\left[b_{0}, b[.\right.
$$

Taking, moreover, into account (50), we get from (52) that

$$
\left.\left.\left|u_{0}(t)\right| \leq \varrho(t-a) \quad \text { for } t \in\right] a, a_{0}\right] \quad \text { and } \quad\left|u_{0}(t)\right| \leq \varrho(b-t) \quad \text { for } t \in\left[b_{0}, b[\text {, }\right.
$$

and thus $u_{0}$ satisfies the conditions

$$
u_{0}(a)=0, \quad u_{0}(b)=0 .
$$

On account of (44) and (48), there exist $\left.\alpha_{0} \in\right] a, a_{0}\left[, \beta_{0} \in\right] b_{0}, b\left[\right.$, and $n_{0}$ such that

$$
a_{n}<\alpha_{0}, \quad \varrho\left(\alpha_{0}-a+\int_{a}^{a_{0}}(s-a)\left|\tilde{q}_{n}(s)\right| d s\right)<1 \quad \text { for } n>n_{0}
$$


and

$$
b_{n}>\beta_{0}, \quad \varrho\left(b-\beta_{0}+\int_{b_{0}}^{b}(b-s)\left|\tilde{q}_{n}(s)\right| d s\right)<1 \quad \text { for } n>n_{0} .
$$

Then it follows from (52) that

$$
\left|\tilde{u}_{n}(t)\right|<1 \quad \text { for } t \in\left[a_{n}, \alpha_{0}\right] \cup\left[\beta_{0}, b_{n}\right], n>n_{0} .
$$

Hence, in view of (46), $\left\|\tilde{u}_{n}\right\|_{\left[\alpha_{0}, \beta_{0}\right]}=1$ for $n>n_{0}$. Taking now into account (50), we get $\left\|u_{0}\right\|_{\left[\alpha_{0}, \beta_{0}\right]}=1$, and thus $u_{0}$ is a nontrivial solution of problem $\left(1_{0}\right)$, (2). However, this contradicts an assumption of the lemma.

\section{Proofs of the main results}

Proof of Theorem 1.1 To prove the theorem, it is sufficient to show that if problem $\left(1_{0}\right),(2)$ has no nontrivial solution, then problem (1), (2) has at least one solution.

Let $a_{0}, b_{0}, \bar{a}_{0}, \bar{b}_{0}, \varrho$, and $r_{0}$ be from the assertions of Lemmas 3.2 and 3.3. Let, moreover, the sequences $\left.\left\{a_{n}\right\}_{n=1}^{+\infty} \subset\right] a, \min \left\{a_{0}, \bar{a}_{0}\right\}\left[\right.$ and $\left.\left\{b_{n}\right\}_{n=1}^{+\infty} \subset\right] \max \left\{b_{0}, \bar{b}_{0}\right\}, b[$ be such that

$$
\lim _{n \rightarrow+\infty} a_{n}=a, \quad \lim _{n \rightarrow+\infty} b_{n}=b .
$$

By virtue of Lemma 3.3, the problem

$$
u^{\prime \prime}=p(t) u ; \quad u\left(a_{n}\right)=0, \quad u\left(b_{n}\right)=0
$$

has no nontrivial solution. Hence, by virtue of Proposition 2.1, the problem

$$
\begin{aligned}
& u_{n}^{\prime \prime}=p(t) u_{n}+q(t), \\
& u_{n}\left(a_{n}\right)=0, \quad u_{n}\left(b_{n}\right)=0
\end{aligned}
$$

has a unique solution $u_{n}$. Moreover, by virtue of Lemma 3.3, the estimate

$$
\left|u_{n}(t)\right| \leq r_{1} \quad \text { for } t \in\left[a_{n}, b_{n}\right]
$$

holds, where

$$
r_{1}=r_{0} \int_{a}^{b}(s-a)(b-s)|q(s)| d s
$$

On the other hand, on account of Lemma 3.1 and (55), we have

$$
(t-a)(b-t)\left|u_{n}^{\prime}(t)\right| \leq r_{2} \quad \text { for } t \in\left[a_{n}, b_{n}\right]
$$

where

$$
r_{2}=r_{1}\left(b-a+\int_{a}^{b}(s-a)(b-s)[p(s)]_{-} d s\right)+\int_{a}^{b}(s-a)(b-s)|q(s)| d s
$$


In view of (53), (55), and (56), the sequence $\left\{u_{n}\right\}_{n=1}^{+\infty}$ is uniformly bounded and equicontinuous in $] a, b[$. Hence, by virtue of the Arzelá-Ascoli lemma, we can suppose, without loss of generality, that

$$
\left.\lim _{n \rightarrow+\infty} u_{n}(t)=u_{0}(t) \quad \text { uniformly in }\right] a, b[,
$$

where $u_{0} \in C(] a, b[)$ and, moreover,

$$
\lim _{n \rightarrow+\infty} u_{n}^{\prime}\left(\frac{a+b}{2}\right)=c_{0}
$$

Taking into account (54), one can easily verify, by a direct calculation, that

$$
\begin{aligned}
u_{n}(t)= & u_{n}\left(\frac{a+b}{2}\right)+\left(t-\frac{a+b}{2}\right) u_{n}^{\prime}\left(\frac{a+b}{2}\right) \\
& +\int_{\frac{a+b}{2}}^{t}\left(\int_{\frac{a+b}{2}}^{s}\left[p(\xi) u_{n}(\xi)+q(\xi)\right] d \xi\right) d s \quad \text { for } t \in\left[a_{n}, b_{n}\right] .
\end{aligned}
$$

Hence, in view of (57) and (58), we get

$$
\begin{aligned}
u_{0}(t)= & u_{0}\left(\frac{a+b}{2}\right)+\left(t-\frac{a+b}{2}\right) c_{0} \\
& \left.+\int_{\frac{a+b}{2}}^{t}\left(\int_{\frac{a+b}{2}}^{s}\left[p(\xi) u_{0}(\xi)+q(\xi)\right] d \xi\right) d s \quad \text { for } t \in\right] a, b[.
\end{aligned}
$$

Thus $u_{0} \in A C_{\mathrm{loc}}^{\prime}(] a, b[)$ and $u_{0}$ is a solution of equation (1).

Further, by virtue of Lemma 3.2 and (55), the inequalities

$$
\left.\left.\left|u_{n}(t)\right| \leq \varrho\left(r_{1}(t-a)+\int_{a}^{t}(s-a)|q(s)| d s+(t-a) \int_{t}^{a_{0}}|q(s)| d s\right) \quad \text { for } t \in\right] a_{n}, a_{0}\right]
$$

and

$$
\left|u_{n}(t)\right| \leq \varrho\left(r_{1}(b-t)+\int_{t}^{b}(b-s)|q(s)| d s+(b-t) \int_{b_{0}}^{t}|q(s)| d s\right) \quad \text { for } t \in\left[b_{0}, b_{n}[\right.
$$

are fulfilled. Hence, on account of (57), we get

$$
\begin{aligned}
& \left.\left.\left|u_{0}(t)\right| \leq \varrho\left(r_{1}(t-a)+\int_{a}^{t}(s-a)|q(s)| d s+(t-a) \int_{t}^{a_{0}}|q(s)| d s\right) \quad \text { for } t \in\right] a, a_{0}\right], \\
& \left|u_{0}(t)\right| \leq \varrho\left(r_{1}(b-t)+\int_{t}^{b}(b-s)|q(s)| d s+(b-t) \int_{b_{0}}^{t}|q(s)| d s\right) \quad \text { for } t \in\left[b_{0}, b[\right.
\end{aligned}
$$

and thus $u_{0}(a)=0$ and $u_{0}(b)=0$. Consequently, $u_{0}$ is a solution of problem (1), (2).

Proof of Theorem 1.2 According to Theorem 1.1, problem (1), (2) has a unique solution $u$. By virtue of Lemma 3.3, the estimate

$$
|u(t)| \leq r_{0} \int_{a}^{b}(s-a)(b-s)|q(s)| d s \quad \text { for } t \in[a, b]
$$


holds. On the other hand, it follows from Lemma 3.1 that

$$
\begin{aligned}
(t-a)(b-t)\left|u^{\prime}(t)\right| \leq & \|u\|_{[a, b]}\left(b-a+\int_{a}^{b}(s-a)(b-s)[p(s)]_{-} d s\right) \\
& \left.+\int_{a}^{b}(s-a)(b-s)|q(s)| d s \quad \text { for } t \in\right] a, b[.
\end{aligned}
$$

The latter two inequalities imply (9) with

$$
r=1+r_{0}\left(b-a+\int_{a}^{b}(s-a)(b-s)[p(s)]_{-} d s\right) .
$$

Proof of Corollary 1.1 By virtue of Theorem 1.1, problems (1), (2) and $\left(10_{n}\right),(2)$ have unique solutions $u$ and $u_{n}$, respectively. Let

$$
v_{n}(t)=u_{n}(t)-u(t) \quad \text { for } t \in[a, b] .
$$

Then it is clear that

$$
\left.v_{n}^{\prime \prime}(t)=p(t) v_{n}(t)+\tilde{q}_{n}(t) \quad \text { for } t \in\right] a, b\left[, \quad v_{n}(a)=0, \quad v_{n}(b)=0,\right.
$$

where

$$
\left.\tilde{q}_{n}(t)=q_{n}(t)-q(t) \quad \text { for } t \in\right] a, b[.
$$

Hence, by virtue of Theorem 1.2,

$$
\left.\left|v_{n}(t)\right|+(t-a)(b-t)\left|v_{n}^{\prime}(t)\right| \leq r \int_{a}^{b}(s-a)(b-s)\left|\tilde{q}_{n}(s)\right| d s \quad \text { for } t \in\right] a, b[\text {. }
$$

Taking now into account (12), (59), and (60), we get (13) and (14).

\section{Competing interests}

The authors declare that they have no competing interests.

\section{Authors' contributions}

All authors read and approved the final manuscript.

\section{Author details}

1 Institute of Mathematics, Academy of Sciences of the Czech Republic, branch in Brno, Žižkova 22, Brno, 616 62, Czech Republic. ${ }^{2}$ Faculty of Mechanical Engineering, Institute of Mathematics, Brno University of Technology, Technická 2, Brno, 616 69, Czech Republic.

\section{Acknowledgements}

Published results were supported by the project 'Popularization of BUT R\&D results and support systematic collaboration with Czech students' CZ.1.07/2.3.00/35.0004 and by Grant No. FSI-S-11-3 'Modern methods of mathematical problem modelling in engineering.' Research was also supported by RVO: 67985840. 
References

1. Kiguradze, IT, Lomtatidze, AG: On certain boundary-value problems for second-order linear ordinary differential equations with singularities. J. Math. Anal. Appl. 101(2), 325-347 (1984)

2. Kiguradze, IT, Shekhter, BL: Singular boundary value problems for second order ordinary differential equations. J. Sov. Math. 43(2), 2340-2417 (1988)

10.1186/1687-2770-2014-13

Cite this article as: Lomtatidze and Opluštil: Fredholm alternative for the second-order singular Dirichlet problem. Boundary Value Problems 2014, 2014:13

Submit your manuscript to a SpringerOpen ${ }^{\circ}$ journal and benefit from:

- Convenient online submission

- Rigorous peer review

- Immediate publication on acceptance

- Open access: articles freely available online

- High visibility within the field

- Retaining the copyright to your article

Submit your next manuscript at $>$ springeropen.com 